\title{
Heterochromatin heteromorphism in Holhymenia rubiginosa (Heteroptera: Coreidae)
}

\author{
María José BReSSA ${ }^{1,3}$, María José FRANCO ${ }^{2}$, María Ayelén TOSCANI ${ }^{1}$ and Alba Graciela PAPESCHI*1,3 \\ ${ }^{1}$ Laboratorio de Citogenética y Evolución, Departamento de Ecología, Genética y Evolución, Facultad de Ciencias Exactas y \\ Naturales, Universidad de Buenos Aires. Int. Güiraldes 2160, C1428EGA, Ciudad Universitaria, Ciudad Autónoma de Buenos Aires, \\ Argentina; e-mail: alpape@ege.fcen.uba.ar \\ ${ }^{2}$ Centro de Investigaciones en Reproducción, Facultad de Medicina, Universidad de Buenos Aires, Buenos Aires, Argentina \\ ${ }^{3}$ Members of the Carrera del Investigador Científico (CONICET)
}

Key words. Coreidae, holokinetic chromosomes, C-banding, fluorescent-banding, karyotype evolution, fluorescent in situ hybridization, rDNA

\begin{abstract}
Heterochromatin is one of the most dynamic components in the genome of species. Previous studies on the heterochromatin content and distribution in Heteroptera (insects with holokinetic chromosomes) have shown that the species belonging to the family Coreidae are interesting model organisms since they show very diverse $\mathrm{C}$ bands patterns. In the present work, we analyzed the C-band pattern in individuals of Holhymenia rubiginosa from different populations collected in different years. This species has the diploid karyotype $2 \mathrm{n}=27 / 28=24+2 \mathrm{~m}+\mathrm{X} 0 / \mathrm{XX}$ (male/female). C-bands are terminally, subterminally or interstitially located on 10-17 chromosomes and a remarkable heterochromatin heteromorphism is observed in the meiotic bivalents: in the presence/absence of bands, in the size of bands and number of bands. A heteromorphism is also inferred in the number of ribosomal genes from the difference in the fluorescent in situ hybridization signals between NOR-homologues. Chiasmata are generally located opposite to conspicuous C-bands, but in some bivalents chiasmata are also observed in close proximity to C-bands. Considering the striking variation in heterochromatin content between individuals and populations it is suggested that heterochromatin should be selectively neutral in H. rubiginosa.
\end{abstract}

\section{INTRODUCTION}

Heterochromatin was defined by Heitz (1928) as the nuclear material that remains condensed throughout the cell cycle. A high proportion of repetitive sequences, late S-phase replication and lack of recombination characterize most of the heterochromatin blocks. It was also evident at the beginning of the nineteenth century that constitutive heterochromatin exerts a repressive effect on the expression of most genes in or near it (position effect variegation, PEV) (Müller, 1930; Henikoff, 1990). However, in the last few years heterochromatin has become the subject of active research because its composition, structure and function are far from unique, and are just beginning to be understood (Dillon, 2004; Huisinga et al., 2006).

From a cytogenetic and evolutionary point of view heterochromatin continues to excite the interest of researchers working on different model organisms. The heterochromatin can vary in composition from highly $\mathrm{A}+\mathrm{T}$ to highly $\mathrm{G}+\mathrm{C}$, and in length from a $2 \mathrm{bp}$ repeat to repeating units of hundreds or thousands of base pairs (Sumner, 2003). Even within species or within a single chromosome heterochromatin can be made up of different types of DNA. In chromosomes with localized centromeres, heterochromatin is generally located at pericentromeric or telomeric positions, and less frequently interstitially. On the other hand, most reports on the dis- tribution pattern of heterochromatin in chromosomes without a discrete centromere (holokinetic chromosomes) describe the presence of telomeric blocks (Mola \& Papeschi, 2006). In the Heteroptera, the classical distribution pattern of heterochromatin is telomeric blocks in some or all the chromosomes. Interstitial C-positive bands are described in a few species and some of them correspond to secondary constrictions and nucleolar organizing regions (NORs). Fluorescent banding with $\mathrm{CMA}_{3}$ reveals that these $\mathrm{C}$-positive bands are generally $\mathrm{G}+\mathrm{C}$ rich (Papeschi \& Bressa, 2006). Cytogenetic data for species belonging to Coreidae suggest that there is a great diversity in heterochromatin amount, composition, and localization in this heteropteran family (Bressa et al., 2005).

The number and location of NORs have been determined by different cytogenetic techniques in relatively few species of Heteroptera. In all of them there is a single pair of NORs, but at different locations: at subterminal or medial positions on an autosomal pair or the sex chromosomes (Papeschi \& Bressa, 2006).

In the present work, we analyzed the $\mathrm{C}$-banding pattern of Holhymenia rubiginosa Breddin; this species has $\mathrm{C}$ positive bands, located in terminal, subterminal, and/or interstitial positions, and a remarkable heterochromatin heteromorphism in all individuals. In addition, the number and location of NORs were determined by fluorescent in situ hybridization (FISH) with an $18 \mathrm{~S}$ rDNA

\footnotetext{
* Corresponding author
} 
probe. These results are discussed in relation to chromosome behaviour, recombination and evolution in order to get a better understanding of the function of heterochromatin in the genetic system of heteropterans.

\section{MATERIAL AND METHODS}

\section{Specimens}

We analyzed 33 males and 13 females of Holhymenia rubiginosa Breddin from different locations in the province of Buenos Aires, Argentina (Table 1).

\section{Chromosome preparations}

The individuals were brought alive to the laboratory and their gonads dissected under a binocular microscope. Some gonads were fixed in $3: 1$ (ethanol : glacial acetic acid), and slides made using squash procedures (Macgregor, 1993).

Spread preparations of mitotic and meiotic chromosomes were made from testes of adult males. The testes were dissected in a saline solution, swollen for 10-20 $\mathrm{min}$ in a hypotonic solution $(0.075 \mathrm{M} \mathrm{KCl})$ and then fixed for $15-30 \mathrm{~min}$ in freshly prepared Carnoy fixative (ethanol : chloroform : acetic acid, $6: 3$ : 1). Cells were dissociated in a drop of $60 \%$ acetic acid with the help of tungsten needles and spread on the slide using a hot plate at $45^{\circ} \mathrm{C}$ (Traut, 1976). Then the preparations were dehydrated in an ethanol series $(70 \%, 80 \%, 96 \%, 30 \mathrm{~s}$ each) and stored at $-20^{\circ} \mathrm{C}$.

\section{C-banding and fluorescent banding}

C-banding and fluorescent banding (DAPI fluorochrome) were then applied to these slides to reveal the constitution of heterochromatin (Papeschi, 1988; Rebagliati et al., 2003). The chromosomes of selected cells at mitotic prometaphase from males (22) and females (14) were measured using the computer application MicroMeasure version 3.3 (Reeves \& Tear, 2000).

\section{Fluorescence in situ hybridization}

Unlabelled $18 \mathrm{~S}$ rDNA probes were generated by PCR using 2 primers, Het 62218s F (5'-TTGCGGTTAAAAAGCTCG-3') and Het 143018s R (5' - TCGGAATTAACCAGACAAATC-3'), custom-made by GibcoBRL Custom Primers (Invitrogen Life Technologies Inc., Buenos Aires, Argentina). The primers were designed according to a consensus sequence $18 \mathrm{~S}$ rDNA from published sequences of eight hemipteran genera: Oncopeltus, Lygus, Spissistilus (Sorensen et al., 1995), Graphosoma (Aleshin et al., 1995), Saldula, Buenoa (Whiting et al., 1997), Triatoma (Marcilla A. et al., unpubl.), Rhaphigaster (Chalwatzis N. \& Zimmermann F.K., unpubl.), using the biological sequence alignment editor Bioedit. PCR was done in a Mastercycler ${ }^{\circledR}$ ep Gradient (Eppendorf AG, Hamburg, Germany). Reactions were carried out in $50 \mu 1$ reaction volumes containing $1 \times$ Taq buffer and 2 U Taq DNA polymerase (Buenos Aires, Argentina), 10 $\mu \mathrm{mol}$ of $\mathrm{dNTP} / \mathrm{L}$ mix, $30 \mathrm{ng} / \mu \mathrm{l}$ of each primer and $100 \mathrm{ng}$ of template genomic DNA extracted from Pachylis argentinus adults (Coreidae, Heteroptera) by the standard procedure of Marchant (1988). An initial denaturation period of $4 \mathrm{~min}$ at $94^{\circ} \mathrm{C}$ was followed by 29 cycles of $1 \mathrm{~min}$ at $94^{\circ} \mathrm{C}, 1 \mathrm{~min}$ at $48^{\circ} \mathrm{C}$, and $1 \mathrm{~min} 15 \mathrm{~s}$ at $72^{\circ} \mathrm{C}$, and by a final extension step of 7 min at $72^{\circ} \mathrm{C}$. The PCR product showed a single band of about $800 \mathrm{bp}$ on a $1 \%$ agarose gel. The band was cut from the gel, and the DNA was extracted using a QIAquick Gel Extraction Kit (Qiagen GmbH, Hilden, Germany). The rDNA probe was labelled by nick translation with biotin 14-dUTP (BioNick Labeling System, Invitrogen Life Technologies Inc., Buenos Aires, Argentina). FISH with biotinylated probe was performed as described in Sahara et al. (1999). Hybridization signals were detected with streptavidin-Cy3 conjugate (Sigma, Saint Louis, USA). The preparations were counterstained with $0.5 \mu \mathrm{g} / \mathrm{ml}$ DAPI (4',6-diamidino-2-phenylindole; Sigma-Aldrich Production $\mathrm{GmbH}$, Buchs, Switzerland $)$ in PBS $(0.15 \mathrm{~mol} / \mathrm{L} \mathrm{NaCl}, 0.05$ $\left.\mathrm{mol} / \mathrm{L} \mathrm{NaH} \mathrm{PO}_{4}, \mathrm{pH} 7.4\right), 1 \%$ Triton $\mathrm{X}-100$ and mounted in antifade (Vectashield Mounting Medium, Vector Laboratories, Inc., Burlingame, USA). The preparations were observed using a Leica DMLB epifluorescence microscope. Black-and-white images of chromosomes were recorded with a CCD camera (Leica DFC350 FX, Leica IM50 Version 4.0, Leica Microsystems Imaging Solutions Ltd. Cambridge, United Kingdom) separately for each fluorescent dye. Images were pseudocoloured (light blue for DAPI and red for Cy3) and superimposed with the aid of an image processing program.

\section{RESULTS}

\section{Karyotype and male meiotic behavior}

Holhymenia rubiginosa has $2 \mathrm{n}=27 / 28=24+2 \mathrm{~m}+$ $\mathrm{X} 0 / \mathrm{XX}$ (male/female) (Fig. 1a, b). The complement comprises 12 pairs of autosomes of decreasing size, a sex chromosome $\mathrm{X}$, and a pair of $\mathrm{m}$ chromosomes, which are the smallest of the complement (Fig. 2a, b). In spermatogonial and oogonial prometaphases (but more remarkably in the former) the largest autosome is much larger than the second one (compare chromosome 1 and 2 in the idiograms); the pair of $\mathrm{m}$ chromosomes is easily recognized (chromosomes 27 and 28 in the female complement, and chromosomes 26 and 27 in the male complement) and the

TABLE 1. Number and provenance of adult males and females specimens analyzed using haematoxylin staining, C-banding and fluorescent banding,

\begin{tabular}{lccc}
\hline Date & \multicolumn{1}{c}{ Location } & No. of males $^{1}$ & No. of females $^{-}$ \\
\hline March, 2002 & La Plata, Buenos Aires (LP-1) & 3 & - \\
October, 2002 & La Plata, Buenos Aires (LP-2) & $6(2)$ & - \\
November, 2002 & La Plata, Buenos Aires (LP-3) & $6(3)$ & - \\
November, 2006 & La Plata, Buenos Aires (LP-4) & 1 & - \\
January, 2003 & 9 de Julio, Buenos Aires (NJ-1) & 1 & - \\
February, 2005 & Florida, Buenos Aires (FL-1) & $1(1)$ & $1(1)$ \\
December, 2005 & C. Universitaria, CABA (CU-1) & $5(5)$ & $6(6)$ \\
March, 2006 & C. Universitaria, CABA (CU-2) & $5(5)$ & 1 \\
April, 2006 & C. Universitaria, CABA ${ }^{2}$ CU-3) & 4 & $5(5)$ \\
January, 2006 & Villa Elisa, Buenos Aires (VE-1) & $1(1)$ & \\
\hline
\end{tabular}

${ }^{1}$ Number of specimens analyzed using C-banding and/or fluorescent banding is indicated in brackets; ${ }^{2}$ CABA - Ciudad Autónoma de Buenos Aires. 

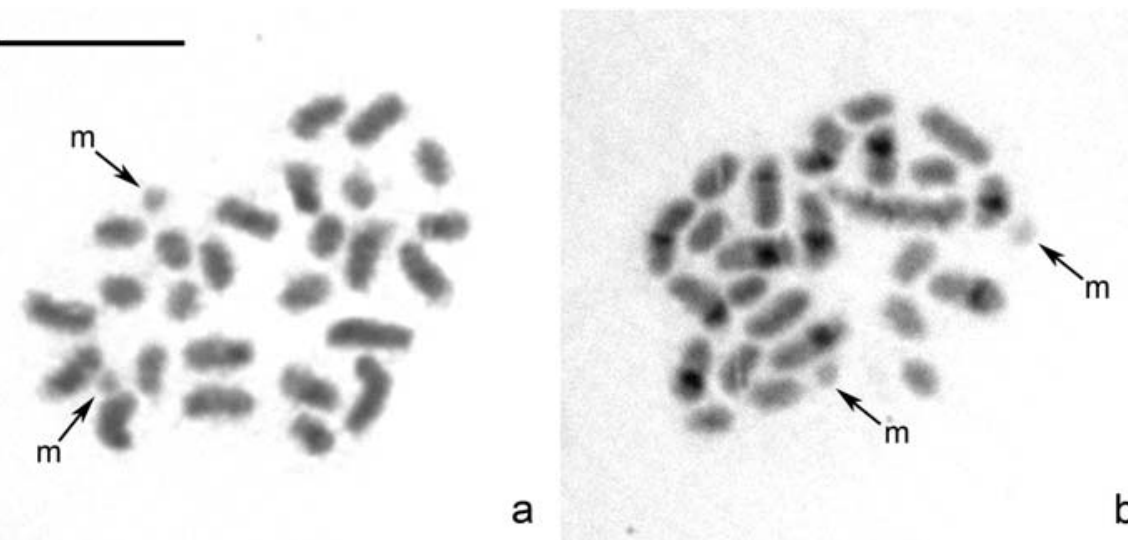

Fig. 1. (a) Oogonial prometaphase (conventional staining). (b) Spermatogonial prometaphase (C-banding). $\mathrm{m}-\mathrm{m}$ chromosomes. Bar $=10 \mu \mathrm{m}$.

$\mathrm{X}$ chromosome cannot be identified by its size (Figs 1a, b, 2a, b).

Male meiosis follows the general pattern for Heteroptera. The $\mathrm{m}$ chromosomes are achiasmatic and associate at late prophase I forming a pseudobivalent (pII). During the first meiotic division the $\mathrm{m}$ chromosomes and the autosomes divide reductionally but the $\mathrm{X}$ chromosome divides equationally (Toscani et al., 2007). During meiosis two bivalents are usually distinguished because of their large size (see below).

There is usually only one chiasma on each autosomal bivalent, which can be terminally or, less frequently, subterminally/interstitially located (Table 2, Fig. 3a-e); mean chiasma frequency per nucleus is 12.24 , with a range between 11.60 and 13.06. The largest bivalents seldom show two terminal chiasmata, and cells with a pair of autosomal univalents with a low frequency (range from 0.03 to 0.17 ) were observed in five individuals from different locations (Table 2).

\section{C-banding and DAPI banding}

In oogonial and spermatogonial prometaphases from 10 to 17 chromosomes show C-bands (Table 3). The variation in the number of chromosomes with detectable C-bands, even within each individual, largely depends on
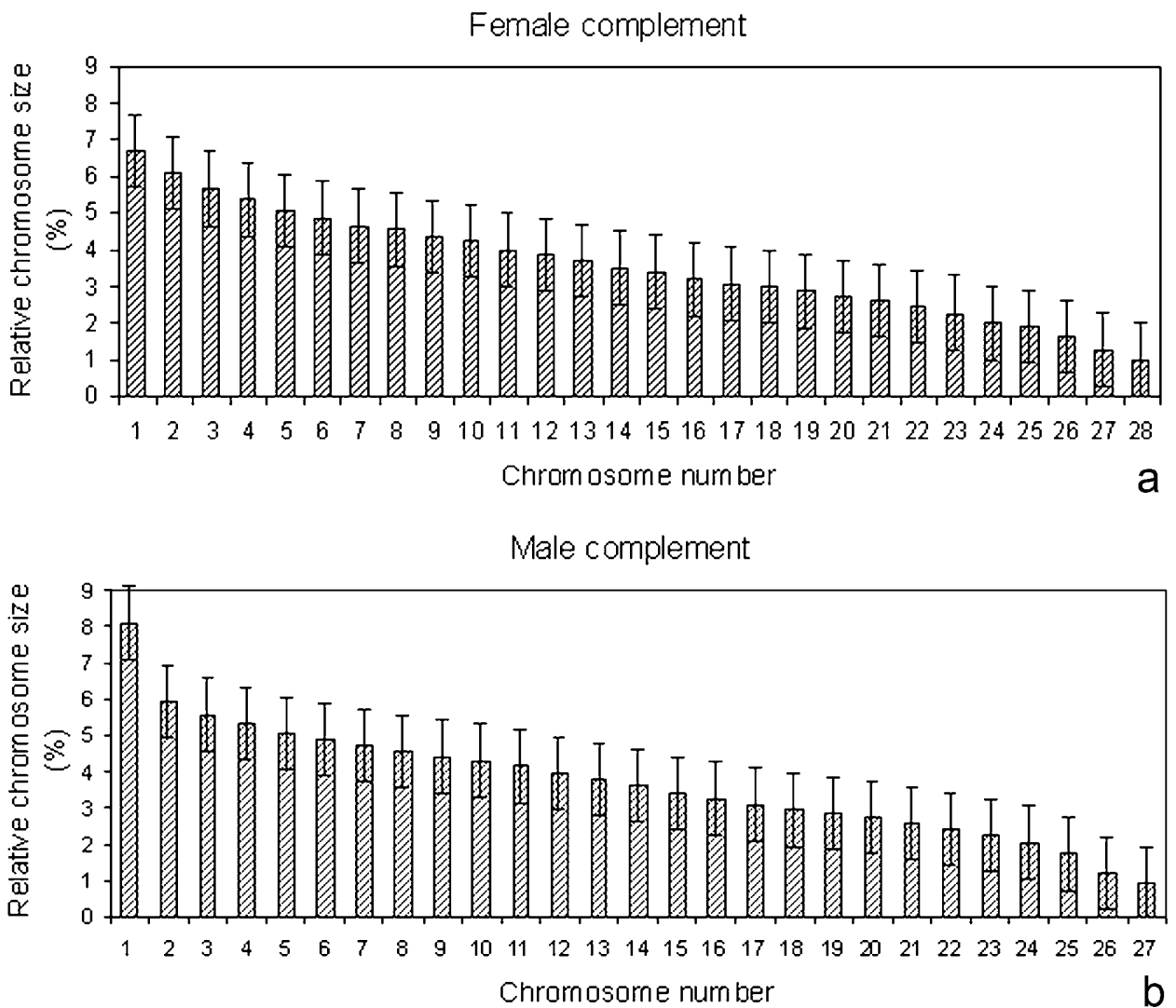

Fig. 2. Female (a) and male (b) idiogram. Sex chromosomes cannot be distinguished during mitosis and the m chromosomes are the smallest of the complement (27-28 in female idiogram, 26-27 in male idiogram). 
TABLE 2. Chiasma frequency and chiasma location in specimens of Holhymenia rubiginosa (specimens with few analyzable cells are not included).

\begin{tabular}{|c|c|c|c|c|}
\hline Individual & $\begin{array}{c}\text { No. of cells at } \\
\text { diakinesis-metaphase I }\end{array}$ & $\begin{array}{c}\text { Mean chiasma } \\
\text { frequency per cell }\end{array}$ & $\begin{array}{c}\text { No. of cells } \\
\text { with univalents }\end{array}$ & $\begin{array}{l}\text { Frequency of bivalents with interstitial- } \\
\text { subterminal chiasmata per individual }\end{array}$ \\
\hline 1 (LP-1) & 31 & 12.70 & 0 & 0.06 \\
\hline 2 (LP-1) & 33 & 12.42 & 1 & 0 \\
\hline 3 (LP-1) & 30 & 12.73 & 0 & 0.07 \\
\hline 4 (LP-2) & 30 & 12.23 & 0 & 0.13 \\
\hline 5 (LP-2) & 31 & 12.09 & 0 & 0.03 \\
\hline 6 (LP-2) & 33 & 12.12 & 4 & 0.12 \\
\hline 7 (LP-2) & 30 & 12.33 & 0 & 0.23 \\
\hline 8 (LP-2) & 30 & 12.20 & 0 & 0.17 \\
\hline 9 (LP-2) & 30 & 12.30 & 0 & 0 \\
\hline 10 (LP-3) & 30 & 13.06 & 0 & 0.23 \\
\hline 11 (LP-3) & 30 & 12.33 & 2 & 0.07 \\
\hline 12 (LP-3) & 30 & 12.20 & 0 & 0.33 \\
\hline 13 (LP-3) & 31 & 12.29 & 0 & 0 \\
\hline 14 (LP-3) & 30 & 12.56 & 0 & 0.07 \\
\hline 15 (LP-3) & 30 & 12.33 & 0 & 0.1 \\
\hline 16 (LP-4) & 26 & 12.08 & 0 & 0.05 \\
\hline 17 (FL-1) & 10 & 12.00 & 0 & 0.06 \\
\hline $18(\mathrm{CU}-1)$ & 10 & 11.60 & 2 & 0.02 \\
\hline $19(\mathrm{CU}-1)$ & 18 & 12.00 & 0 & 0.07 \\
\hline $20(\mathrm{CU}-1)$ & 36 & 11.83 & 6 & 0.05 \\
\hline $21(\mathrm{CU}-1)$ & 13 & 12.00 & 0 & 0.22 \\
\hline $22(\mathrm{CU}-2)$ & 23 & 12.09 & 0 & 0.21 \\
\hline $23(\mathrm{CU}-2)$ & 24 & 12.04 & 0 & 0.25 \\
\hline
\end{tabular}

the condensation degree of the chromosomes. In particular, in three females from Villa Elisa (VE-1), three males from Ciudad Universitaria (CU-1, CU-2) and one male from Villa Elisa (VE-1); one of the largest chromosomes shows three tiny $\mathrm{C}$-bands, and in some mitotic cells this chromosome is associated with the nucleolus.

In male meiotic cells, four to nine autosomal bivalents out of the twelve have C-bands at interstitial, subterminal or terminal positions. A striking feature of the C-band pattern in $H$. rubiginosa is the heteromorphism in size, number, and position of heterochromatic bands (Fig. 3a-e). In addition, the DAPI-band pattern agrees completely with the C-band pattern (not shown). According to the kind of heteromorphism different types of autosomal bivalents can be recognized. The two largest bivalents show very tiny bands that are not always identifiable (Fig. $3 a-e$, bivalents type 1 and 2) and one of them is associated with the nucleolus (Fig. 3d-e). There are mediumsized bivalents heteromorphic for the presence/absence of one band, i.e. only one of the two homologues has a C-positive band (Fig. 3a-e, bivalent type 3); there are medium sized bivalents heteromorphic for the size of the band, i.e., the C-band is of different size in each member of the pair of homologues (Fig. 3a-e, bivalent type 4). In the individual from Florida (FL-1), one bivalent is heteromorphic for the number of bands, i.e. one homologue shows two conspicuous C-bands while the other has only one C-band (Fig. 3d-e, bivalent type 5); and another bivalent is heteromorphic for band position, i.e. the $\mathrm{C}$-band is subterminal in one homologue and terminal in the other member of the pair (Fig. 3d-e, bivalent type 6). The $\mathrm{m}$ chromosomes are always $\mathrm{C}$-negative and the $\mathrm{X}$ chromosome has a little C-positive band at a subterminal position, which is not always discernible. Finally, in two individuals from Ciudad Universitaria (CU-2) one completely $\mathrm{C}$-negative bivalent is heteromorphic for chromosome size (Fig. 3a, e, bivalent type 7).

The analysis of chiasma position in relation to C-bands shows that chiasmata are generally located opposite C-bands ( $87 \%$ of 203 bivalents); however, in a low number of bivalents chiasmata are adjacent to the heterochromatin blocks (13\%).

\section{Fluorescent in situ hybridization (FISH)}

The rDNA probe hybridizes in the terminal region of one of the largest autosomal pairs (Fig. 4a-e). A clear difference in the signal is detected between the pair of homologues in all the cells of the individuals analyzed (Fig. 4c, d), and even in one individual only one signal is detected in all cells both at mitotic prometaphases and meiotic stages (Fig. 4a, b). As described in the previous section the largest autosomal pairs do not have conspicuous C-bands; depending on their condensation two or three very tiny bands interstitially located can be detected. The hybridization signal, on the other hand, has a terminal location. This implies that the observed heteromorphism in the hybridization signal has no correspondence with heteromorphism of heterochromatin. 

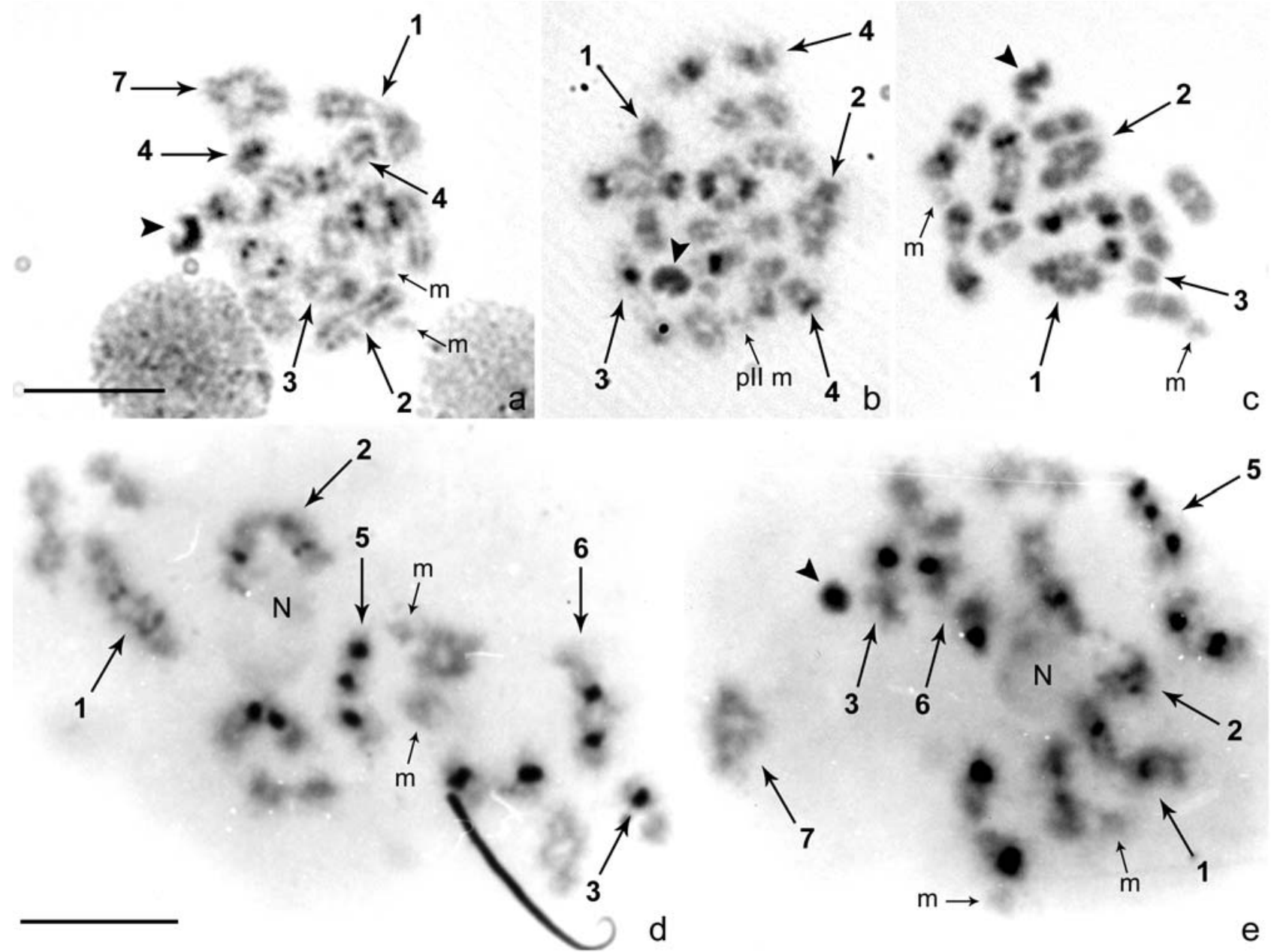

Fig. 3. Male meiotic cells at diakinesis (a-e) after C-banding. In (d) the X chromosome is missing. Different bivalent types are identified by numbers: bivalent types 1 and 2, largest bivalents; type 3, heteromorphic bivalent for presence/absence of C-bands; type 4, heteromorphic bivalents for C-bands size; type 5, heteromorphic bivalents for number of C-bands; type 6, heteromorphic bivalent for C-bands position; type 7, heteromorphic bivalents for chromosome size. Arrowheads show the $\mathrm{X}$ chromosome; $\mathrm{m}-\mathrm{m}$ chromosomes; pII m - m pseudobivalent; $\mathrm{N}$ - nucleolus. Bar $=10 \mu \mathrm{m}$.

\section{DISCUSSION AND CONCLUSIONS}

Species of Coreidae are characterized by the possession of holokinetic chromosomes and the post-reductional behaviour of sex chromosomes in male meiosis. The diploid number of the family ranges from 13 to 28 with a mode of $2 n=21$ in males, which is present in 47 out of the 108 species cytogenetically analyzed (43.5\%). Coreidae are also characterized by the possession of a pair of $\mathrm{m}$ chromosomes, which are reported in $81.9 \%$ of the species. The most common sex chromosome systems of the family are X0/XX (male/female) $(64.3 \%)$ and the multiple system $\mathrm{X}_{1} \mathrm{X}_{2} 0 / \mathrm{X}_{1} \mathrm{X}_{1} \mathrm{X}_{2} \mathrm{X}_{2} \quad(32.1 \%)$ (Papeschi \& Bressa, 2006, 2007). Holhymenia rubiginosa has $2 \mathrm{n}=$ $27 / 28=24+2 \mathrm{~m}+\mathrm{X} 0 / 24+2 \mathrm{~m}+\mathrm{XX}$. This chromosome number deviates from the modal number for the family because of the presence of three additional chromosome pairs. Holhymenia clavigera, the only other species in the genus cytogenetically analyzed, shares the same diploid number $2 \mathrm{n}=27$ (male) (Colombo \& Bidau, 1985). Considering the modal number for Coreidae as the ancestral one, the karyotype of $H$. rubiginosa and $H$. clavigera may have originated by the fragmentation of three autosomal pairs.

Most reports on C-positive heterochromatin in Heteroptera show that $\mathrm{C}$-bands are terminally located (Papeschi \& Bressa, 2007). However, different distribution patterns have been recently described. In a few species, an interstitial C-positive band on only one autosomal pair is recorded, and there are few examples, in which all or almost all the autosomes show interstitial heterochromatin blocks (Franco et al., 2006; Grozeva et al., 2006). Holhymenia rubiginosa belongs to this category since the heterochromatin blocks are subterminally located in many autosomal pairs. In agreement with most Heteroptera, autosomal bivalents of $H$. rubiginosa usually only have one chiasma, which is generally located at a terminal position, and in most cases chiasmata are observed at the opposite end of the chromosome to the heterochromatic band. The relationship between chiasma position and heterochromatin blocks has been explained in two different ways: (a) localization of chiasmata at one end of a chromosome and the lack of recombination at the other allowed the accumulation of heterochromatin in the latter 
TABLE 3. Characterization of individuals by the total number of mitotic chromosomes/autosomal bivalents (II) with C-bands per cell, and number of heteromorphic chromosomes/autosomal bivalents observed per cell.

\begin{tabular}{|c|c|c|c|c|}
\hline Individual & $\begin{array}{c}\text { Chromosomes with } \\
\text { C-bands }{ }^{1}\end{array}$ & $\begin{array}{l}\text { Heteromorphic } \\
\text { chromosomes }\end{array}$ & $\begin{array}{c}\text { Autosomal II with } \\
\text { C-bands }\end{array}$ & $\begin{array}{c}\text { Heteromorphic } \\
\text { autosomal II }\end{array}$ \\
\hline \multicolumn{5}{|l|}{ Females } \\
\hline $1(\mathrm{CU}-1)$ & 14 & - & - & - \\
\hline $2(\mathrm{CU}-2)$ & 15 & - & - & - \\
\hline 3 (VE-1) & $14-16$ & 1 large with 3 bands ${ }^{a}$ & - & - \\
\hline 4 (VE-1) & $10,13,14$ & 1 large with 3 bands & - & - \\
\hline $5(\mathrm{VE}-1)$ & 14 & 1 large with 3 bands $^{a}$ & - & - \\
\hline $6(\mathrm{VE}-1)$ & $13-15,17$ & - & - & - \\
\hline \multicolumn{5}{|l|}{ Males } \\
\hline 1 (LP-2) & 12 & - & 6 & $3^{\mathrm{b}}$ \\
\hline 2 (LP-2) & 16 & - & 8 & $6^{\mathrm{b}, \mathrm{c}}$ \\
\hline 3 (LP-3) & 18 & - & 9 & $5^{b, c}$ \\
\hline 4 (LP-3) & 16 & - & 8 & $3^{b}$ \\
\hline 5 (LP-3) & 18 & - & 9 & $4^{\mathrm{b}, \mathrm{c}}$ \\
\hline $5(\mathrm{~F}-1)$ & 10 & - & $6-7$ & $2^{\mathrm{c}, \mathrm{e}}$ \\
\hline $6(\mathrm{CU}-1)$ & $10,12,14$ & - & $5-7$ & $2-4^{b}$ \\
\hline 7 (CU-1) & $8-10$ & - & $4-5$ & $1-3^{b, c}$ \\
\hline $8(\mathrm{CU}-1)$ & 12 & 1 large with 3 bands & $5-6$ & $1-4^{b, c}$ \\
\hline $9(\mathrm{CU}-2)$ & 16 & 1 large with 3 bands & $4-8$ & $4^{b, c, d}$ \\
\hline $10(\mathrm{CU}-2)$ & $10-13,15-17$ & 1 large with 3 bands & $5-7$ & $1-4^{b, c, d}$ \\
\hline $11(\mathrm{CU}-2)$ & $14-18$ & - & $7-9$ & $3-6^{b, c}$ \\
\hline $12(\mathrm{VE}-1)$ & 10,15 & 1 large with 3 bands & $6-8$ & $1-2^{b, c}$ \\
\hline
\end{tabular}

${ }^{1}$ numbers in italics are inferred from meiotic cells; ${ }^{a}$ the largest mitotic chromosome with three tiny bands is associated with the nucleolus; ${ }^{\mathrm{b}}$ bivalents heteromorphic in C-bands size; ${ }^{\mathrm{c}}$ bivalents heteromorphic in number of C-bands (presence/absence); ${ }^{\mathrm{d}}$ bivalent heteromorphic in chromosome length; ${ }^{\mathrm{e}}$ bivalent heteromorphic in number of C-bands (two bands/one band).

(a consequence of the absence of recombination); and (b) heterochromatin exerts a negative effect on recombination and constrains chiasmata to the opposite end of the chromosome (heterochromatin is the cause of the lack of recombination). Thus, heterochromatin accumulation can be the consequence or the cause of lack of recombination, respectively. Our observations on $H$. rubiginosa do not give complete support to either of these hypothesis. Although most chiasmata are located opposite heterochromatin bands, some bivalents show recombination next or very close to heterochromatin.

The most striking feature of the pattern of the distribution of heterochromatin in H. rubiginosa is the remarkable heteromorphism for the presence/absence, size and number of C-positive bands. This heteromorphism was found in all individuals belonging to the different populations, which were sampled at different times (see Material and methods). Of the maximum number of nine autosomal pairs that were observed with heterochromatin blocks, up to two can be heteromorphic for the presence/absence of bands (bivalent type 3), up to three for the size of the bands (bivalent type 4), one for the number of bands (bivalent type 5), and one for band position (bivalent type 6). Since most autosomal pairs are similar in size, it is not possible to be certain whether the heteromorphic pairs are always the same. Furthermore, up to two bivalents are heteromorphic in chromosome length, and the size difference between homologues cannot be assigned to heterochromatic bands, since they lack detectable C-bands.
It is not possible to define specific karyomorphs because each individual seems to have a different C-banding pattern, but certain cytotypes have a much greater level of block amplification than others. Taking into account the independent assortment of each chromosome pair during meiosis, together with the different possibilities of gamete combinations that will give rise to the next generation and assuming no negative effect of the heterochromatin on fitness, a large diversity of cytotypes is predicted. Our observations seem to agree with this prediction suggesting no selective advantage or disadvantage for the different chromosome complements.

Many authors have argued that satellite DNA, which is located in constitutive heterochromatin, is fundamental to the pairing process in meiosis. In $H$. rubiginosa heterochromatin variation was not associated with pachytene pairing since meiosis is completely regular (Toscani et al., 2007). The low frequency of cells with a pair of univalents falls within the range observed in other heteropteran insects (Papeschi \& Mola, 1990; Mola \& Papeschi, 1993; Bressa et al., 1999, 2001, 2002). Since any of the medium-sized autosomal pairs can be present as univalents no relationship seems to exist between heterochromatin content and chiasma distribution. This gives further support to the previous observation that heterochromatin does not affect chromosome pairing.

In Triatoma sordida and $T$. infestans (Reduviidae) variations in heterochromatin content between and within populations constitute an important mechanism of karyotypic change but the differentiation through gain or loss 

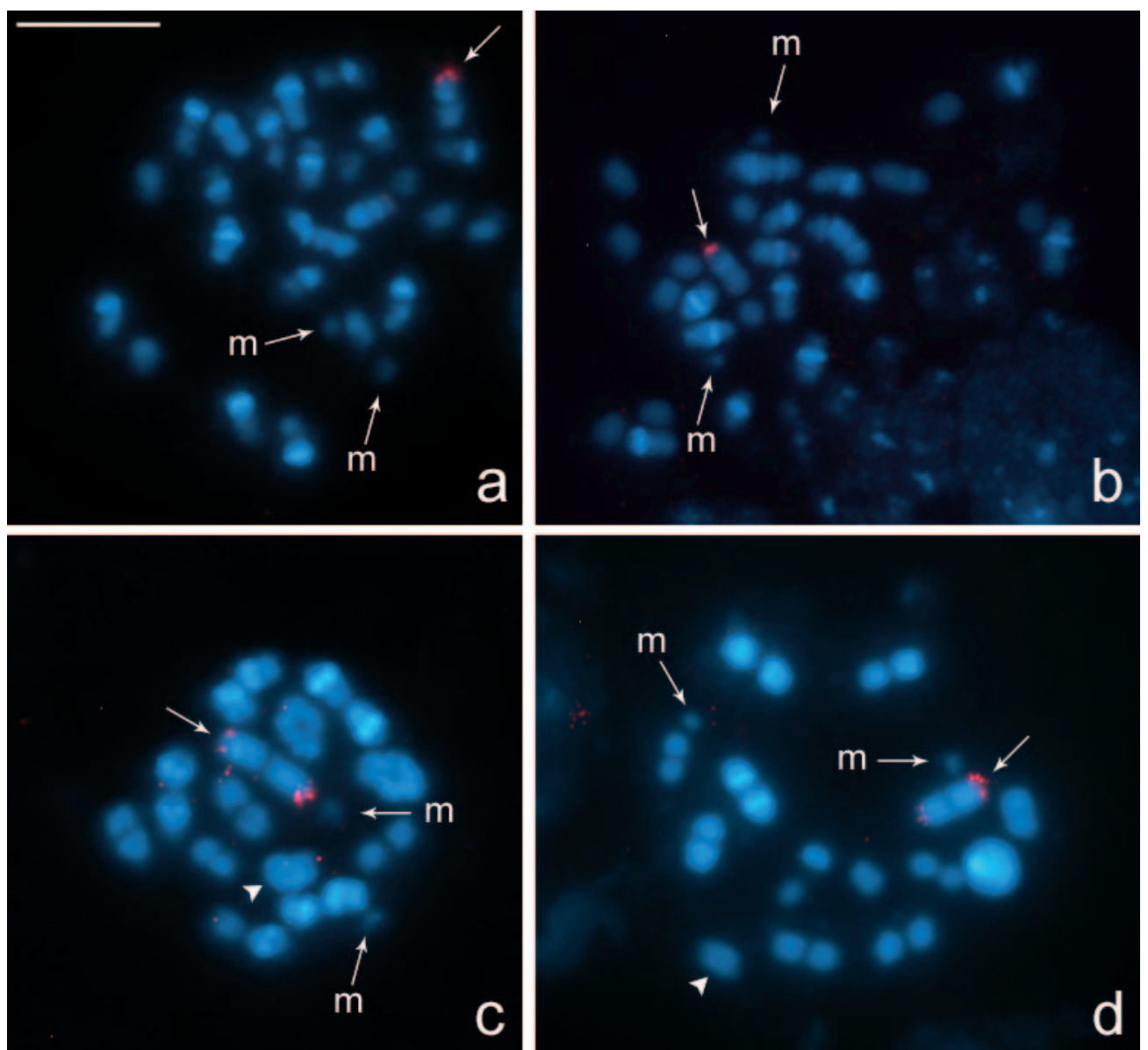

Fig. 4. FISH with $18 \mathrm{~S}$ rDNA probe in spread preparations of male germ cells (blue, chromosomes counterstained with DAPI; red, hybridization signals). (a-b) Spermatogonial prometaphases. Arrows show the hybridization signals of the probe (red) on one of the largest autosomes. (c-d) Diakinesis. Arrows show one of the largest autosomal bivalents with hybridization signals of the probe (red) of different intensity in each homologue. $\mathrm{m}-\mathrm{m}$ chromosomes. Bar $=10 \mu \mathrm{m}$.

of heterochromatin is not considered as a primary mechanism of reproductive isolation (Panzera et al., 1995; Rebagliati et al., 1998). According to King (1993), rearrangements, which do not affect fertility (such as addition or deletion of heterochromatin), have no difficulty in forming polymorphisms.

All the individuals belonging to the different populations showed heterochromatin heteromorphism. There is no information on the vagility of $H$. rubiginosa but since some of the populations are $50 \mathrm{~km}$ apart gene flow between the populations is unlikely. Thus, the variation in the heterochromatin content developed independently in the different populations. In addition, this heterochromatin heteromorphism occurred since our first studies on the species in 2002 and is still present. This leads us to suggest that the heterochromatin is either selectively neutral or even positively heterotic.

In eukaryotic genomes, the number of copies of ribosomal genes is highly variable: some organisms with small genomes have less than 100 copies of rDNA, while some plants and amphibians have more than 10,000 copies. Polymorphisms in the number of copies is normal, both between homologues in the same individual and between individuals. In some species the rDNA can be confined to a single site on a pair of homologous chromosomes, but quiet often it is spread over several chromosomes (Sumner, 2003; Proença et al., 2005). Up to now only one NOR per haploid genome is reported in heteropterans. The location of rDNA genes in the terminal region of one autosomal pair in $H$. rubiginosa agrees with previous reports on heteropteran species. However, NORs have also been reported at the terminal end of sex chromosomes or at interstitial positions on one autosomal pair (Dias de Campos Severi-Aguiar \& Vilela de AzeredoOliveira, 2005; Papeschi \& Bressa, 2006).

Our results indicate a differential intensity in the hybridization signals between both members of an autosomal pair in $H$. rubiginosa, reaching an extreme situation in one individual in which only one chromosome showed an hybridization signal and its homologue did not. This heteromorphism probably reflects variations in the number of copies of the rDNA. Furthermore, the NOR heteromorphism accords with the already described heteromorphism in heterochromatin content. These observations suggest that the amplification of DNA sequences could be a particular feature of the genome of $H$. rubiginosa. Particular sequences may have been amplified to a different degree, and are found in different positions on 
the chromosomes of the complement, and this amplification could have taken place through different mechanisms such as replication slippage, unequal crossing-over, or duplicative transposition of mobile elements after their activation. Future studies of more populations and over long periods of time will give us a better understanding of the role of heterochromatin in the genetic systems of these heteropteran species.

ACKNOWLEDGEMENTS. MJB and AGP are members of CONICET. This work was supported by grants from University of Buenos Aires (X317) and CONICET (PIP 5261). The authors wish to thank F. Marec (Institute of Entomology, BC AVCR, České Budějovice, Czech Republic) for the training received in his laboratory and for FISH protocols, and the financial support from CONICET (Res. N²311/2004).

\section{REFERENCES}

Aleshin V.V., VladychensKaya N.S., Kedrova O.S., Milyutina I.A. \& Petrov N.B. 1995: Phylogeny of invertebrates deduced from 18S rRNA comparisons. Mol. Biol. 29: 843-855.

Bressa M.J., Papeschi A.G., Mola L.M. \& Larramendy M.L. 1999: Meiotic studies in Dysdercus Guérin Méneville 1831 (Heteroptera: Pyrrhocoridae). I. Neo-XY in Dysdercus albofasciatus Berg 1878, a new sex chromosome determining system in Heteroptera. Chromosome Res. 7: 503-508.

Bressa M.J., Papeschi A.G., Mola L.M. \& Larramendy M.L. 2001: Autosomal univalents as a common meiotic feature in Jadera haematoloma and Jadera sanguinolenta (Heteroptera: Rhopalidae: Serinethinae). Eur. J. Entomol. 98: 151-157.

Bressa M.J., Papeschi A.G. \& Larramendy M.L. 2002: Meiotic studies in Lygaeus alboornatus Blanchard (Heteroptera, Lygaeidaae: Lygaeinae). Caryologia 55: 19-23.

Bressa M.J., Larramendy M. \& Papeschi A.G. 2005: Heterochromatin characterization in five species of Heteroptera. Genetica 124: 307-317.

Colombo P.C. \& Bidau C.J. 1985: Estudios cromosómicos en heterópteros argentinos. I. Los cromosomas meióticos de cinco especies de Coreidae. Physis 43: 29-40.

Dias de Campos Severi-Aguiar G. \& Vilela de AzeredoOliveira M.T. 2005: Localization of rDNA sites in holocentric chromosomes of three species of triatomines (Heteroptera, Triatominae). Genet. Mol. Res. 4: 704-709.

Dillon N. 2004: Heterochromatin structure and function. Biol. Cell 96: 631-637.

Franco M., Bressa M.J. \& Papeschi A.G. 2006: Karyotype and male meiosis in Spartocera batatas (Fabricius) and meiotic behaviour of multiple sex chromosomes in Coreidae, Heteroptera. Eur. J. Entomol. 103: 9-16.

Grozeva S., Nokkala S. \& Simov N. 2006: First evidence of sex chromosome prereduction in male meiosis in the Miridae bugs (Heteroptera). Folia Biol. 54: 9-12.

Hertz E. 1928: Das Heterochromatin der Moose. Jb. Wiss. Bot. 69: $762-818$.

Henikoff S. 1990: Position-effect variegation after 60 years. Trends Genet. 6: 422-426.

Huisinga K.L., Brower-Toland B. \& Elgin S.C.R. 2006: The contradictory definitions of heterochromatin: transcription and silencing. Chromosoma 115: 110-126.

King M. 1993: Species Evolution. The Role of Chromosome Change. Cambridge University Press, Cambridge, xxi +336 pp.

MACGREGOR H.C. 1993: An Introduction to Animal Cytogenetic. Chapman \& Hall, London, 238 pp.
MARCHANT A.D. 1988: Apparent introgression of mitochondrial DNA across a narrow hybrid zone in the Caledia captiva species-complex. Heredity 60: 39-46.

Mola L.M. \& Papeschi A.G. 1993: Meiotic studies in Largus rufipennis (Castelnau) (Largidae, Heteroptera): frequency and behaviour of ring bivalents, univalents and $\mathrm{B}$ chromosomes. Heredity 71: 33-40.

Mola L.M. \& PAPeschi A.G. 2006: Holokinetic chromosomes at a glance. $B A G$ 17: $17-33$.

MüLLER H.J. 1930: Types of visible variations induced by X-rays in Drosophila. J. Genet. 22: 299-334.

Panzera F., Perez R., Panzera Y., Alvarez F., Scvortzoff E. \& Salvatella R. 1995: Karyotype evolution in holocentric chromosomes of three related species of triatomines (Hemiptera - Reduviidae). Chromosome Res. 3: 143-150.

PAPESCHI A.G. 1988: C-banding and DNA content in three species of Belostoma (Heteroptera) with large differences in chromosome size and number. Genetica 76: 43-51.

Papeschi A.G. \& BRessa M.J. 2006: Evolutionary cytogenetics in Heteroptera. J. Biol. Res. 5: 3-21.

Papeschi A.G. \& Bressa M.J. 2007: Classical and molecular cytogenetics in Heteroptera. In Mohan R.M. (eds): Research Advances in Entomology. Kerala, pp. 1-9.

Papeschi A.G. \& Mola L.M. 1990: Meiotic studies in Acanonicus hahni (Stål) (Coreidae, Heteroptera) I. Behaviour of univalents in desynaptic individuals. Genetica 80: 31-38.

Proença S., Collares-Pereira M.J. \& Serrano A. 2005: Chromosome evolution in tiger beetles: karyotypes and localization of $18 \mathrm{~S}$ rDNA loci in Neotropical Megacephalini (Coleoptera, Cicindelidae). Genet. Mol. Biol. 28: 725-733.

Rebagliati P., Papeschi A.G., Mola L.M., Pietrokovsky S., Gajate P., Botazzi V. \& Wisnivesky-Colli C. 1998: Comparative meiotic studies in Triatoma sordida (Stål) and T. guasayana Wygodzinsky \& Abalos (Reduviidae, Heteroptera). Mem. Inst. Oswaldo Cruz 93: 309-315.

Rebagliati P., Papeschi A.G. \& Mola L.M. 2003: Meiosis and fluorescent banding in Edessa meditabunda and E. rufomarginata (Heteroptera: Pentatomidae: Edessinae). Eur. J. Entomol. 100: $11-18$.

REEves A. \& TEAR J. 2000: MicroMeasure for Windows, version 3.3. Free program distributed by the authors over the internet from http://www.colostate.edu/Depts/Biology/MicroMeasure. version 3.3.

Sahara K., Marec F. \& Traut W. 1999: TTAGG telomeric repeats in chromosomes of some insects and other arthropods. Chromosome Res. 7: 449-460.

Sorensen J.T., Campbell B.C., Gill R.J. \& Steffen-Campbell J.D. 1995: Auchenorrhyncha ("Homoptera"), based upon 18S rDNA phylogeny: Eco-evolutionary and cladistic implications within pre-Heteropterodea Hemiptera (s.1.) and a proposal for new monophyletic suborders. Pan-Pac. Entomol. 71: 31-60.

Sumner A.T. 2003: Chromosomes: Organization and Function. Blackwell Science, Malden, ix $+287 \mathrm{pp}$.

Toscani M.A., Pigozzi M.I., Bressa M.J. \& Papeschi A.G. 2007: Synapsis with and without recombination in the male meiosis of the leaf-footed bug Holhymenia rubiginosa (Coreidae, Heteroptera). Genetica DOI 10.1007/s10709-007-9159-0:

Traut W. 1976: Pachytene mapping in the female silkworm Bombyx mori L. (Lepidoptera). Chromosoma 58: 275-284.

Whiting M.F., Carpenter J.C., Wheeler Q.D. \& Wheeler W.C. 1997: The Strepsiptera problem: phylogeny of the holometabolous insect orders inferred from $18 \mathrm{~S}$ and $28 \mathrm{~S}$ ribosomal DNA sequences and morphology. Syst. Biol. 46: 1-68.

Received June 6, 2007; revised and accepted September 5, 2007 